\title{
Taklimakan Desert nocturnal low-level jet: climatology and dust activity
}

\author{
Jin Ming Ge ${ }^{1}$, Huayue Liu ${ }^{1,2}$, Jianping Huang ${ }^{1}$, and Qiang Fu ${ }^{1,3}$ \\ ${ }^{1}$ Key Laboratory for Semi-Arid Climate Change of the Ministry of Education and \\ College of Atmospheric Sciences, Lanzhou University, Lanzhou, 730000, China \\ ${ }^{2}$ Hebei Province Meteorological Service Center, Shijiazhuang, 005021, China \\ ${ }^{3}$ Department of Atmospheric Sciences, University of Washington, Seattle, WA 98105, USA \\ Correspondence to: Jianping Huang (hjp@1zu.edu.cn)
}

Received: 3 March 2016 - Published in Atmos. Chem. Phys. Discuss.: 22 March 2016

Revised: 26 May 2016 - Accepted: 3 June 2016 - Published: 24 June 2016

\begin{abstract}
While nocturnal low-level jets (NLLJs) occur frequently in many parts of the world, the occurrence and other detailed characteristics of NLLJs over the Taklimakan Desert (TD) are not well known. This paper presents a climatology of NLLJs and coincident dust over the TD by analyzing multi-year ERA-Interim reanalysis and satellite observations. It is found that the ERA-Interim dataset can capture the NLLJs' features well by comparison with radiosonde data from two surface sites. The NLLJs occur in more than $60 \%$ of nights, which are primarily easterly to east-northeasterly. They typically appear at 100 to $400 \mathrm{~m}$ above the surface with a speed of 4 to $10 \mathrm{~m} \mathrm{~s}^{-1}$. Most NLLJs are located above the nocturnal inversion during the warm season, while they are embedded in the inversion layer during the cold season. NLLJs above the inversion have a strong annual cycle with a maximum frequency in August. We also quantify the convective boundary layer (CBL) height and construct an index to measure the magnitude of the momentum in the CBL. We find that the magnitude of momentum in the lower atmosphere from the top of the surface layer to the top of mixed layer is larger for NLLJ cases than for non-NLLJ cases, and in the warm season the downward momentum transfer process is more intense and rapid. The winds below the NLLJ core to the desert surface gain strength in summer and autumn, and these summer and autumn winds are coincident with an enhancement of aerosol optical depth. This indicates that the NLLJ is an important mechanism for dust activity and transport during the warm season over the Taklimakan.
\end{abstract}

\section{Introduction}

The Taklimakan Desert (TD) is one of the largest deserts and located farther from an ocean than any other desert in the world. It occupies the central part of the Tarim Basin in northwestern China, extending about $1000 \mathrm{~km}$ from east to west and $400 \mathrm{~km}$ from north to south (Fig. 1) with a dry continental climate (Huang et al., 2016). Most of the TD area is composed of shifting sand dunes, and it is the most intense dust aerosol source in Asia (Gao and Washington, 2009; Zhang et al., 2003). The TD is of particular interest not only because of its large contribution to the global dust emission (Uno et al., 2009; Yumimoto et al., 2009) but also because of its very unique orography and prevailing winds. The prevailing wind direction in the low-level atmosphere of the TD is easterly and northeasterly (Fig. 1), which is consistent with the dominant direction of motion of the sand dunes. The elevation of the TD is about $0.8 \mathrm{~km}$ above sea level (a.s.1.) at the northeast side of the Tarim Basin, increasing gradually to $1.5 \mathrm{~km}$ a.s.l. at the southwest area. The basin is open on its eastern side, while the other three sides are surrounded by the high relief of mountains and plateaus with an average elevation over $4.5 \mathrm{~km}$. The prevailing northeasterly, low-altitude winds limit the flow of low-level dust out of this region much of the time. However, former studies have indicated that dust from the TD can be lofted above $5 \mathrm{~km}$ into the upper troposphere (Ge et al., 2014; Huang et al., 2007) and subsequently transported over long distances and around the globe by the westerlies (Huang et al., 2008; Uno et al., 2009). This long-lasting dust aerosol can perturb the energy 


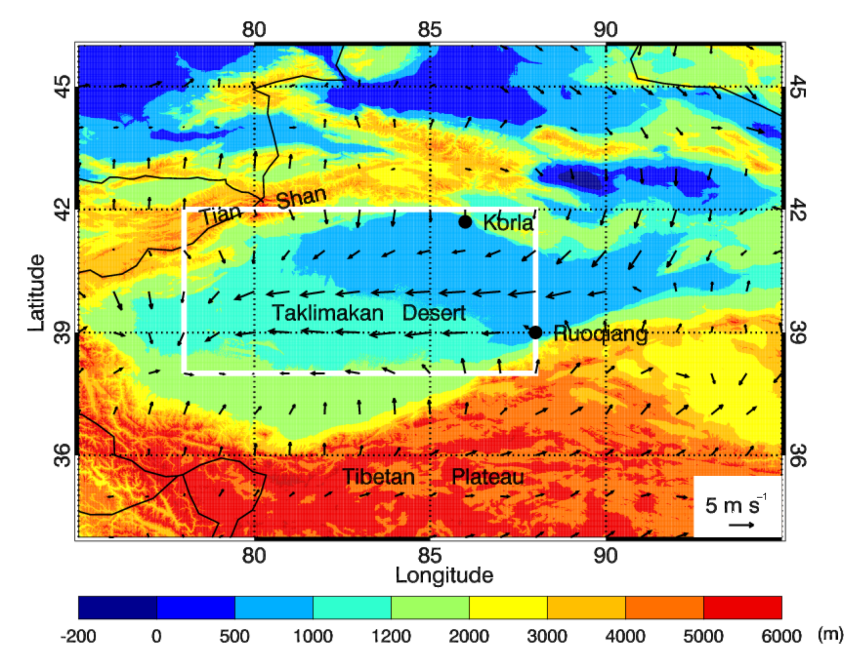

Figure 1. Map of the Taklimakan Desert region with its topography and annual mean wind at $850 \mathrm{hPa}$.

balance of the Earth system through its direct radiative effects on solar and terrestrial radiation (Fu et al., 2009; Ge et al., 2011, 2010; Huang et al., 2014), indirect radiative effects via its influence on physical properties of clouds (Huang et al., 2014; Lohmann and Feichter, 2005; Su et al., 2008), and semi-direct effects by heating the dust layer (Huang et al., 2009, 2014). Thus, high concentrations of elevated dust and its long-range transport from the Taklimakan may play an important role in climate and climate change (Huang et al., 2008; Ling et al., 2014). To better understand dust emission, transport and the influence on climate will require more exploration of the local and mesoscale meteorological processes over this dust source region.

Dust emission processes are controlled by meteorology and surface properties, such as surface wind, soil texture, moisture content, surface roughness, and vegetation (Ginoux et al., 2001; Knippertz and Todd, 2012). A surface wind that exceeds a particle-size-dependent speed threshold is a condition for dust emission (Shao et al., 2011). Above the threshold the dust emission flux is highly sensitive to wind speed (Chen et al., 2013; Lu and Shao, 1999; Tegen, 2003). Synoptic cold fronts are known to lead to strong surface winds, resulting in dust storms over the Taklimakan and Gobi deserts (Sun et al., 2001). Another mechanism that can lead to strong surface winds in semi-arid and desert regions is through the formation of a nocturnal low-level jet (NLLJ) (Fiedler et al., 2013; Rife et al., 2010).

NLLJs are generally characterized as a relatively thin layer with highest wind speeds in a core between 300 and $600 \mathrm{~m}$ above ground level (a.g.l.), while there are usually minima in wind speed 1.0 to $2.0 \mathrm{~km}$ above the core (Rife et al., 2010). A diurnal cycle is a common and well-documented feature of the NLLJ, with onset and cessation times generally in the early evening and midmorning, respectively. Maximum speeds occur around 00:00 to 03:00 local time. Nocturnal low-level jets with diurnal variability form primarily by two mechanisms. One mechanism is the forcing by changes in baroclinicity, which occurs in the differential heating and cooling regions such as slope terrain, coastal areas, and weather fronts (Baas et al., 2009; Stensrud, 1996; Washington and Todd, 2005). The other is related to the decoupling of winds from the surface friction, and subsequent recoupling due to diurnally varying eddy viscosity. This is the initial oscillation mechanism (IO) as advanced by Blackadar (1957) and Van de Wiel et al. (2010). The formation of NLLJs is favored over relatively flat terrain in arid and semi-arid regions. When these essentially local forcing mechanisms exist on a large scale over relatively uniform, level terrain such as the Taklimakan, the NLLJ can extend to the meso- and synoptic scales and may couple to mid-tropospheric winds, thus promoting long-range transport of dust particles. A remarkable feature of the NLLJ is its breakdown after sunrise, when the NLLJ momentum is mixed to the surface, and thus wind speed near the surface is greatly increased (Fiedler et al., 2013; Schepanski et al., 2009). The strong surface wind will blow dust particles up from the desert surface, and the same turbulent mixing will also loft these dust particles to the upper level of the boundary layer, promoting horizontal transport. Therefore, the NLLJ may play an important role in the both dust emission and transport (Allen and Washington, 2014; Heinold et al., 2015; Knippertz, 2008; Tegen et al., 2013; Todd et al., 2008).

Much work has been done to address the features of the NLLJ, demonstrating a link between NLLJs and dust suspension and their contribution to dust emission over northern Africa (Allen and Washington, 2014; Fiedler et al., 2013; Schepanski et al., 2009; Washington and Todd, 2005). Since the TD has a hyper-arid environment and relatively flat terrain, strong radiative cooling during the night in this region can stabilize the near-surface layer and at least partly decouple the air from the surface layer friction, which will provide a favorable condition for NLLJ formation. We anticipate that the frictional decoupling after sunset with a subsequent inertial oscillation may play an important role in the formation of NLLJ for this area. However, there have been very few NLLJ studies over the Taklimakan region. Rife et al. (2010) examined the Tarim Basin NLLJ, but they only focused on its diurnal variation for July. Du et al. (2014) simulated diurnal variations in Tarim Basin NLLJs during early summer from 2006 to 2011 by using the Weather Research and Forecasting (WRF) model. In this paper, we present an NLLJ detection algorithm and show the climatology and seasonal variation in NLLJ over the Taklimakan by using the ERA-Interim reanalysis data. Satellite-based aerosol optical depth (AOD) above the Taklimakan is also analyzed to explore the effect of this NLLJ on dust emission from the desert surface. 


\section{Data}

The essential data for the characterization of NLLJs over the TD are the latest global atmospheric reanalysis fields of the ERA-Interim data on the model levels. These are produced by the European Centre for Medium-Range Weather Forecasts (ECMWF), covering the data-rich period since 1979 and continuing in real time. Compared with the previous reanalysis data from ECMWF, ERA-Interim has many substantial improvements on the representation of the hydrological cycle, the quality of the stratospheric circulation, and the handling of biases and changes in the observing system (Dee et al., 2011). The horizontal resolution of the dataset is about $80 \mathrm{~km}$ with 60 vertical levels from the surface up to $0.1 \mathrm{hPa}$. The 6-hourly daily wind speeds and temperatures with a spatial resolution of $1^{\circ} \times 1^{\circ}$ from 2000 to 2013 were analyzed in this study. We choose the ERA-Interim reanalysis for the climatological study of NLLJs, because surface observations are very sparse due to the remoteness and harsh environment of the TD and ERA-Interim can provide sufficient vertical resolution.

Radiosonde data from two surface sites, Korla $\left(86.08^{\circ} \mathrm{E}\right.$, $41.45^{\circ} \mathrm{N}$ ) and Ruoqiang $\left(88.10^{\circ} \mathrm{E}, 39.02^{\circ} \mathrm{N}\right.$ ) (see Fig. 1), were also used in this study. The radiosondes at these two sites are launched at 08:00 and 20:00 Beijing time (BJT, $8 \mathrm{~h}$ ahead of UTC) and have been operating for more than 50 years. The quality-controlled dataset is updated through 2012. We compared ERA-Interim horizontal wind speed with soundings at 00:00 UTC to validate reanalysis data.

The Multi-angle Imaging SpectroRadiometer (MISR) onboard the Terra satellite, which crosses the Equator at 10:30 in its descending node, covers a swath of approximately $360 \mathrm{~km}$ wide at the Earth's surface and obtains global coverage in about 9 days. By taking advantage of the nine widely spaced angles, MISR can distinguish the top-of-theatmosphere (TOA) reflectance contributions from the surface and atmosphere and successfully retrieve aerosol optical properties over bright surfaces (Diner et al., 2005). In this study, we used level 3 daily AOD from 2000 through 2013 at $0.5^{\circ}$ by $0.5^{\circ}$ resolution to obtain the climatology of AOD and its monthly variation over the Taklimakan.

\section{Detection of NLLJs}

The mean annual cycle of MISR-based AOD and the ERAInterim wind speed at $10 \mathrm{~m}$ above surface, averaged over the TD region (see white box in Fig. 1) for 2000-2013, are shown in Fig. 2. It is obvious that dust loading over the TD has a clear seasonal variation. The AOD peaks in April and May with a monthly median value of $\sim 0.5$, while it decreases to a minimum in November and December with a monthly median value of $\sim 0.2$. We can also see that the AOD at the 95th percentile for the month with minimum median value can exceed 0.7 , demonstrating that a large amount

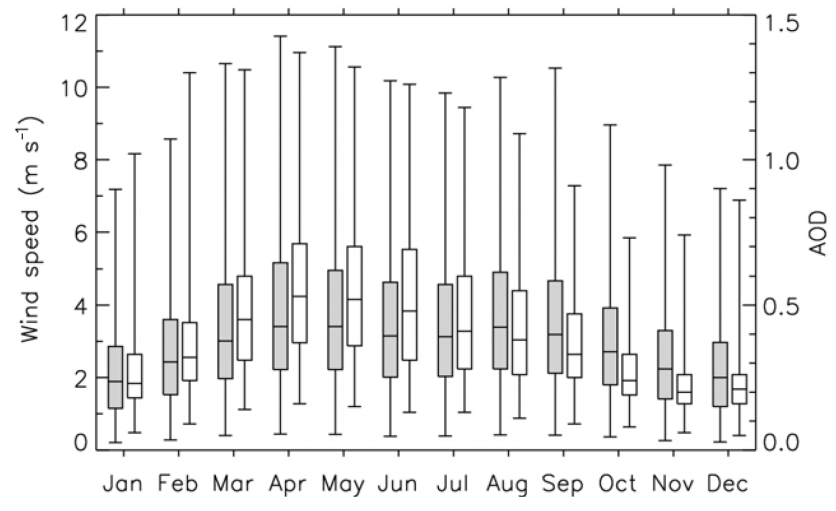

Figure 2. Annual cycles of wind speed (gray bars) and AOD (white bars) from 2000 through 2013 over the Taklimakan Desert. The horizontal line through each box represents that monthly median value; the top and bottom of the boxes mark 75th and 25th percentiles, respectively; and whiskers mark the 95th and 5th percentiles.

of dust can be emitted over the TD throughout the year. The generation of dust aerosol, as well as the consequent particle concentration, is highly dependent on the surface wind speed. A study by Ge et al. (2014) indicated a strong relationship between AOD and near-surface wind over this region. Figure 2 clearly shows that the monthly median value of winds has the same trend as the AOD. Similar to the large spread of AOD, the wind speed also has a wide range in each month.

Note that the annual mean circulation at $850 \mathrm{hPa}$ (Fig. 1) shows a band of high wind speeds in the central Taklimakan. Figure 3 shows the vertical-latitudinal distribution of annual mean wind speeds at 00:00 UTC (06:00 LT) for the longitudes of 82,85 , and $88^{\circ} \mathrm{E}$. It reveals that there is a maximum wind core centered near $40^{\circ} \mathrm{N}$ at about $300-400 \mathrm{~m}$ a.g.l. with a wind speed exceeding of $6.5 \mathrm{~m} \mathrm{~s}^{-1}$. It can extend over $10^{\circ}$ in longitude and over $1^{\circ}$ in latitude. Such a nighttime jet core occurs widely and frequently over the TD. This phenomenon motivates us to examine the details and climatology of NLLJs over the TD region and investigate the potential effects of NLLJs on dust emission.

Before we use the ERA-Interim dataset to characterize the mesoscale episodes of NLLJs occurring over the TD, it is necessary to validate the reanalysis data first. We compared radiosonde data at the Ruoqiang and Korla sites with ERAInterim winds at the grids nearest to the observations sites during the period 2000 through 2012, when both the reanalysis and validated sounding data are available. Figure 4 shows the comparison of mean vertical wind speed profiles from reanalysis to a 13-year subset of sounding data. We can see that the representation of the vertical wind structure in ERAInterim is reasonably good when compared with radiosondes. Importantly, the reanalysis data can reasonably well approximate the height of the maximum low-level winds, although ERA-Interim underestimates the NLLJ winds at Ruoqiang but overestimates them at Korla. We also compared the 


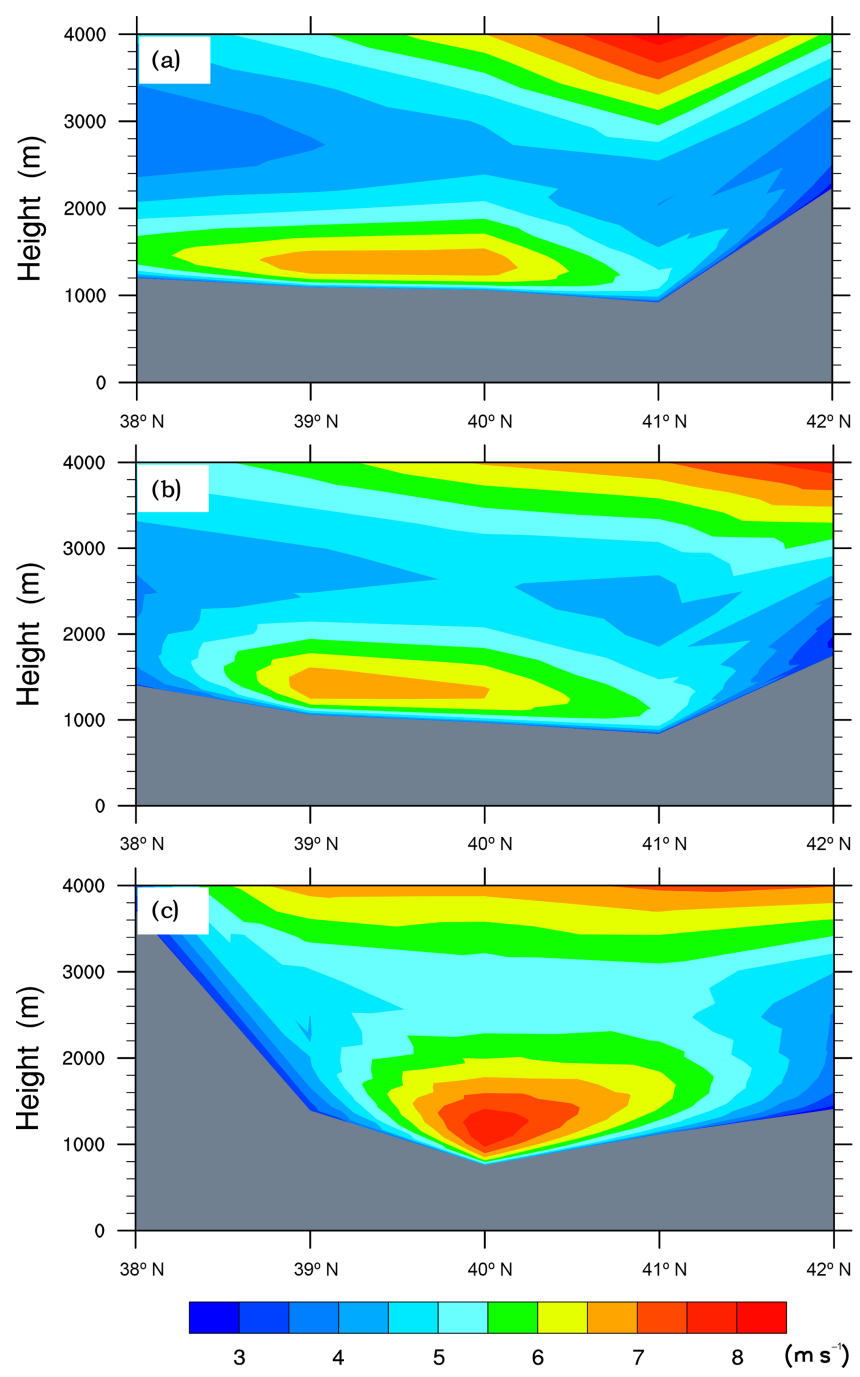

Figure 3. Latitude-height cross sections of annual mean wind speed at three longitudes of (a) $82^{\circ} \mathrm{E}$, (b) $85^{\circ} \mathrm{E}$, and (c) $88^{\circ} \mathrm{E}$ from ERAInterim reanalysis averaged over 2000-2013. Gray areas represent the terrain elevation.

time series of wind speeds from reanalysis and radiosondes at 100 and $600 \mathrm{~m}$ a.g.l. (not shown), and calculated the correlation coefficients and root-mean-square errors (RMSEs). Ruoqiang has a higher correlation coefficient $(0.51)$ for the layer of $600 \mathrm{~m}$ a.g.l., while the RMSE of $4.9 \mathrm{~m} \mathrm{~s}^{-1}$ at Korla is about $0.5 \mathrm{~m} \mathrm{~s}^{-1}$ smaller than that at Ruoqing. Thus, we may expect that ERA-Interim adequately represents the wind structures over the TD.

In order to investigate the climatology of NLLJs over the $\mathrm{TD}$, a set of objective criteria for automatically identifying their occurrences need to be specified. In the literature, many criteria have been applied for identifying LLJs associated with different formation mechanisms, datasets used, and definitions of LLJ (Bonner, 1968; Stull, 1988; Banta et al., 2002; Baas et al., 2009). These include the range of maximum wind

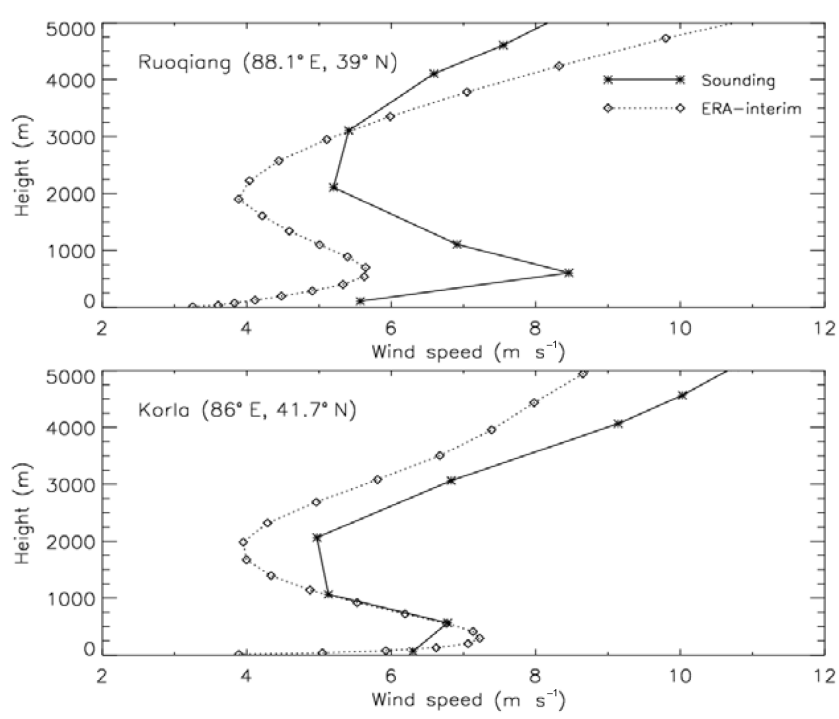

Figure 4. Mean wind speed profiles at 00:00 UTC based on radiosondes (solid line) and ERA-Interim (dotted line) at (a) Ruoqiang and (b) Korla sites for 2000-2012.

height, threshold of wind speed at the jet core, and strength of vertical wind shear. Here we developed an algorithm to detect the NLLJs from the ERA-Interim reanalysis data by partly following the criteria given in Fiedler et al. (2013) and Ranjha et al. (2013), where the ERA-Interim reanalysis data were used to identify LLJs. First, a temperature inversion condition is identified and the inversion top height $\left(H_{\mathrm{i}}\right)$ is determined by scanning each temperature profile by following the protocol proposed by Kahl (1990). $H_{\mathrm{i}}$ must be above the third model level, i.e., roughly $60 \mathrm{~m}$ (a.g.l.). This criterion generally ensures that the lowest atmospheric layers are stable and that the surface frictional drag on the air flowing above it is reduced. Second, the maximum wind speed below $1500 \mathrm{~m}$ a.g.l. and its height $\left(H_{\mathrm{j}}\right)$ are determined. The jet heights are confined to less than $1500 \mathrm{~m}$ following Fiedler et al. (2013). However, reducing this criterion to $900 \mathrm{~m}$ decreases the NLLJ occurrence frequency by only $1 \%$. Third, a wind speed minimum must exist above the NLLJ but below $5 \mathrm{~km}$ a.g.l. with a value $60 \%$ or less relative to the wind speed of the jet core. This condition is a combination and simplification of the second and third criteria proposed by Ranjha et al. (2013), which is a description of LLJ wind shear and ensures that identified NLLJs always have jet-like profiles.

\section{Climatology of NLLJs}

By applying these criteria to the 14-year ERA-Interim data, we found that the NLLJ commonly appears over the Taklimakan and other adjacent arid regions. Figure 5 shows the monthly mean frequency of NLLJs for the TD and surrounding areas along with contours of jet core speed. It is inter- 

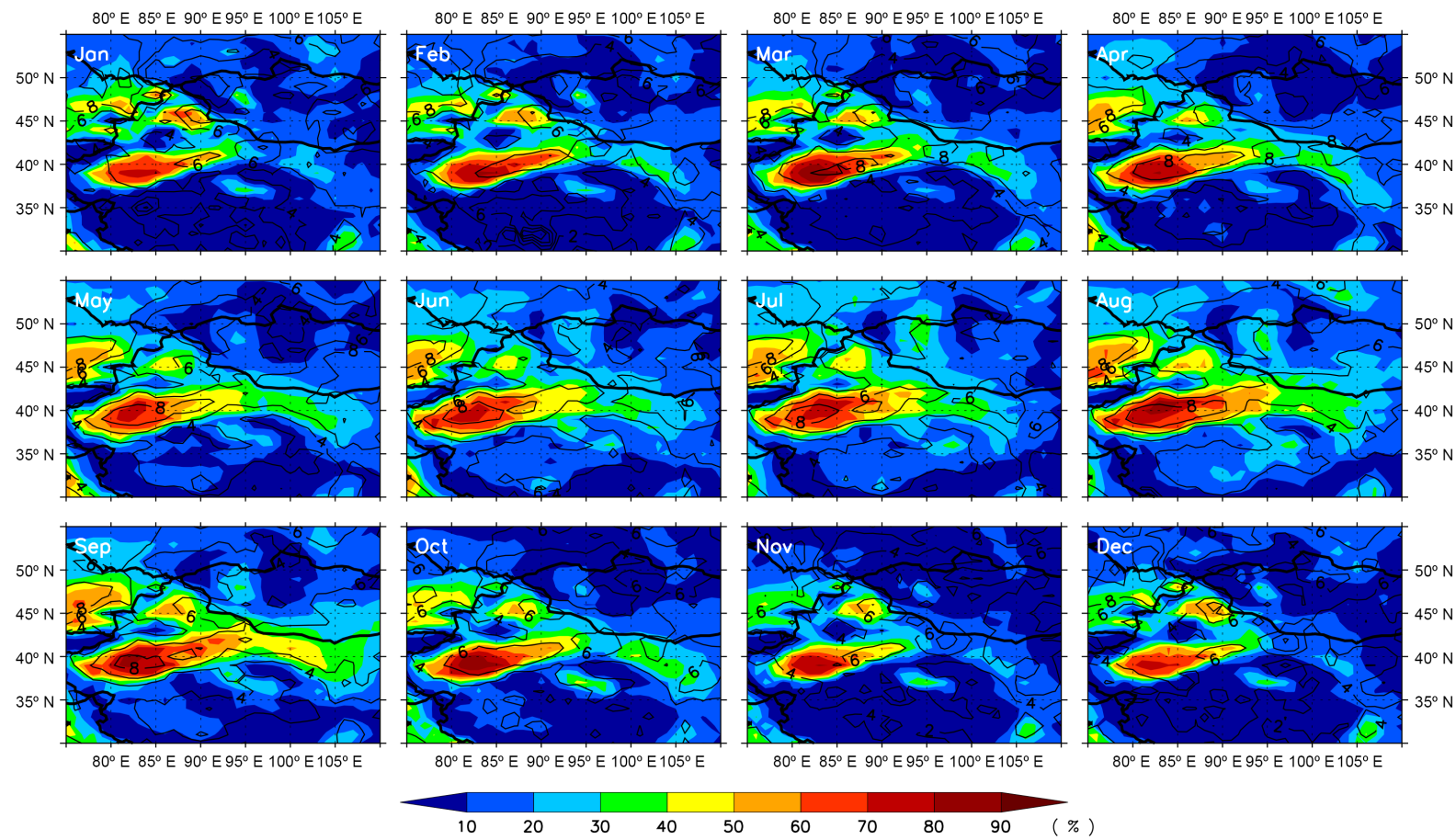

Figure 5. Monthly mean occurrence of NLLJs (colors) with jet core wind speed (contours) at 00:00 UTC by applying the NLLJ detection algorithm to the ERA-Interim reanalysis data for 2000-2013.

esting to note that the NLLJs' occurrence frequency distribution derived from this identification method is closely related to the topography and land surface type. One can see that the main feature of Fig. 5 is a frequency mode with values greater than $60 \%$ appearing in the entire Tarim Basin throughout the year. The geographical distribution of NLLJs can extend eastward from the main mode over the TD to the Loess Plateau along the north slope of the Tibetan Plateau with decreasing frequency of occurrence toward the east. There are also two other high-frequency modes located near the TD region. One is in the Jungar Basin, located in northern Xinjiang, which is a semi-arid area. The other is over desert centered at $76^{\circ} \mathrm{E}, 46^{\circ} \mathrm{N}$ in Kazakhstan. It is also obvious that there is rough colocation of maxima in NLLJ wind speed and frequency. Figure 5 indicates that the jet detection algorithm is successful. The NLLJ is a frequent mesoscale weather phenomenon over the TD and adjacent desert basins.

Figure 6 shows the climatological statistics of (a) jet height, (b) core speed, (c) seasonal variation, and (d) jet direction. Typically, the NLLJ occurs in a very shallow layer. About $67 \%$ of the jet cores are located between 120 and $400 \mathrm{~m}$ a.g.l.; $75 \%$ of the jet core speeds fall between 4 and $10 \mathrm{~m} \mathrm{~s}^{-1}$. The median values of the jet height and jet core speed are $269 \mathrm{~m}$ and $6 \mathrm{~m} \mathrm{~s}^{-1}$, respectively. By comparison, the median values of the NLLJ height and core speed derived from ERA-Interim data for northern Africa (Fiedler et al., 2013) are $350 \mathrm{~m}$ and $10 \mathrm{~m} \mathrm{~s}^{-1}$, which are higher and greater than those over the Taklimakan, respectively. Figure $6 \mathrm{c}$ illus- trates the monthly climatology of jet height, jet core maximum speed, and inversion height. We can see that all these three parameters have clear seasonal variations. The jet speed generally follows the trend of jet height that increases gradually from the cold season to warm season and has a maximum in August. The tendency for stronger NLLJs to occur at higher levels is the same as the tendencies found in other places (Banta et al., 2002; Baas et al., 2009; Fiedler et al., 2013). According to Blackadar's classical theory of IO (Blackadar, 1957), the nocturnal inversion plays an important role in reducing eddy viscosity and decoupling the air aloft in the planetary boundary layer from the surface boundary layer. It thus causes a frictionless layer at the top of the inversion, which is the initial condition for the formation of NLLJ. However, we note that the jet can be found at different heights, which could be above the inversion top or embedded in the inversion layer (Andreas et al., 2000; Baas et al., 2009). Figure $6 c$ shows that the inversion height has an opposite seasonal trend to that of jet height. The inversion height has minimum values in the summer season and can be as thick as $600 \mathrm{~m}$ in later autumn and winter, which is much higher than the jet height of about $230 \mathrm{~m}$. Our analysis indicates that about half of the identified NLLJ cores are above the top of inversion and the other half were embedded or partially embedded in the inversion layer. The low solar elevation angle and high desert surface reflectivity during the cold season would result in less sensible heat and thus a shallower daytime boundary layer but a thicker nocturnal in- 
(a) NLLJ height

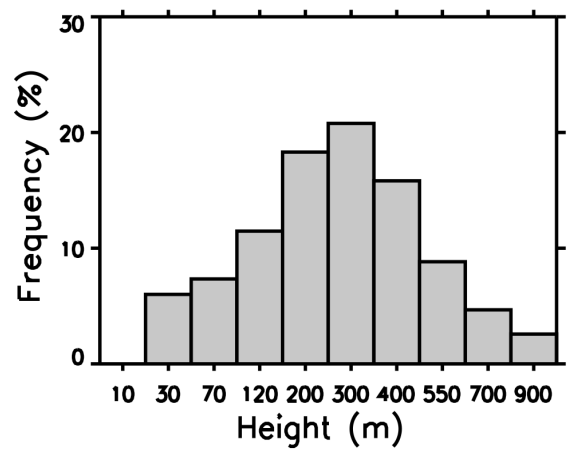

(c) NLLJ seasonal result

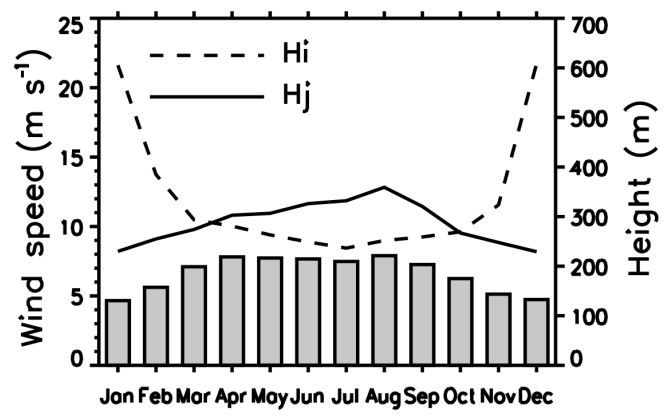

(b) NLLJ core speed

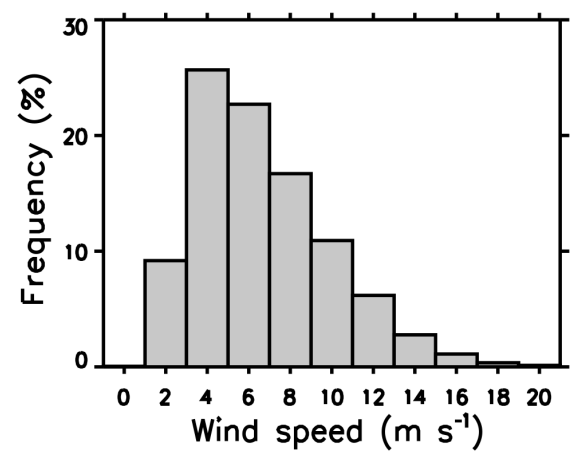

(d) NLLJ wind rose

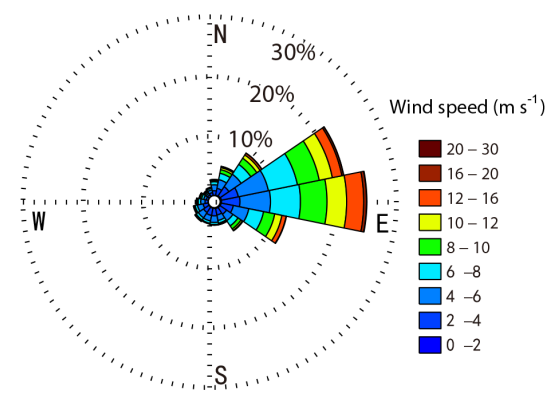

Figure 6. Climatological features of NLLJ over the Tarim Basin $\left(38-42^{\circ} \mathrm{N}, 78-88^{\circ} \mathrm{E}\right)$. (a) Frequency distribution of NLLJ height. (b) Frequency distribution of NLLJ speed. (c) Monthly mean jet core speed (gray bars), NLLJ core height (solid line), and inversion height (dashed line). (d) Jet core wind direction and speed distribution at 00:00 UTC (i.e., 05:30 LT) from ERA-Interim reanalysis from 2000 through 2013.

version layer. In these cases the NLLJ occurs a few hundred meters above the surface, where the layer is well stratified after sunset.

The wind rose in Fig. 6d shows that the prevailing wind direction of the jet core is narrowly distributed between eastnortheast and east-southeast; $67 \%$ of NLLJs over all seasons are within the four sectors between 40 and $120^{\circ}$. This narrow angular NLLJ directional distribution is mainly confined by the topography.

\section{NLLJ effects on dust emission}

Considering that the emission of dust initially develops in the surface boundary layer and is proportional to third or fourth power of the surface wind speed, it is expected that the NLLJ can affect dust production if we can find that NLLJs have impacts on near-surface wind speed and variability. Recent studies (Allen and Washington, 2014; Heinold et al., 2015; Knippertz, 2008; Schepanski et al., 2009) have indicated that the breakdown of the NLLJ over Africa can induce the downward mixing of momentum during the evolution of the boundary layer in midmorning and cause enhancement of near-surface wind speed. Here, we firstly compared the midmorning surface wind speed distribution coincident with

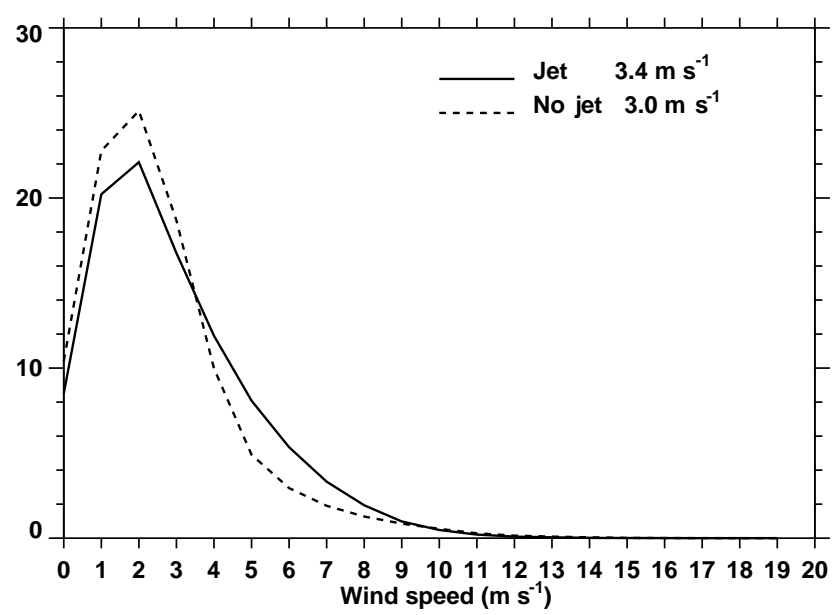

Figure 7. Frequency distribution of $10 \mathrm{~m}$ wind speed at 06:00 UTC (i.e., roughly at 11:30 LT) over the Tarim Basin.

the appearance of NLLJ with that when no NLLJ was detected. Ideally, this would have been calculated for 10:00 LT to observe the maximum effect, but only 6-hourly ERA data were available. Figure 7 shows the near-surface wind speed frequency distribution at 06:00 UTC (i.e., 11:30 LT) over the Taklimakan. We can see an obvious shift of wind speed to- 

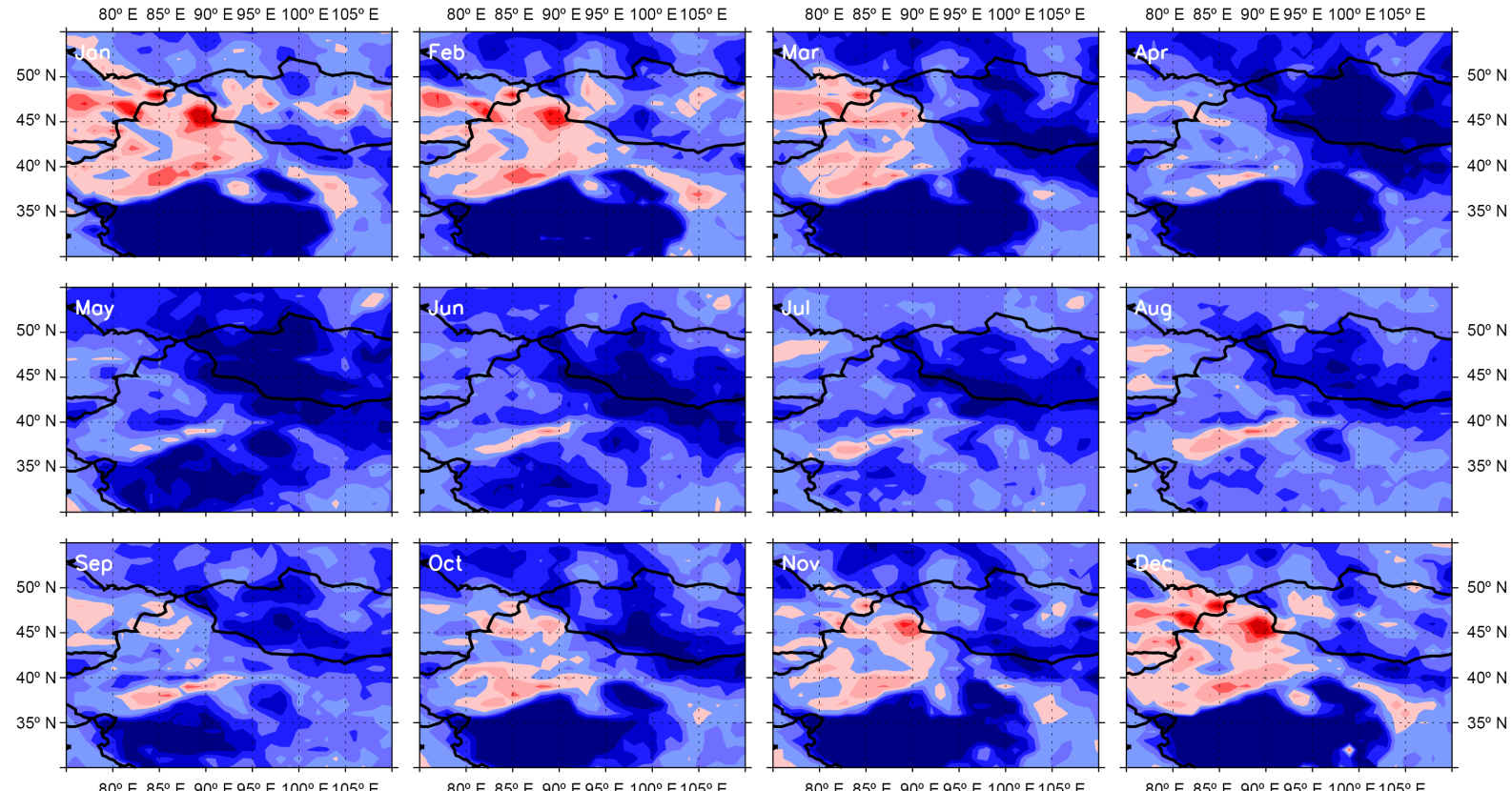

$80^{\circ} \mathrm{E} 85^{\circ} \mathrm{E} 90^{\circ} \mathrm{E} 95^{\circ} \mathrm{E} 100^{\circ} \mathrm{E} 105^{\circ} \mathrm{E}$

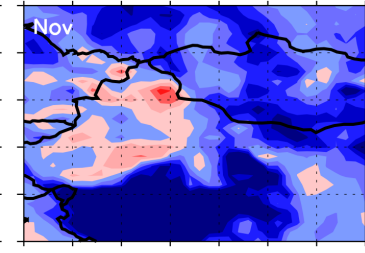

$80^{\circ} \mathrm{E} 85^{\circ} \mathrm{E} 90^{\circ} \mathrm{E} 95^{\circ} \mathrm{E} 100^{\circ} \mathrm{E} 105^{\circ} \mathrm{E}$

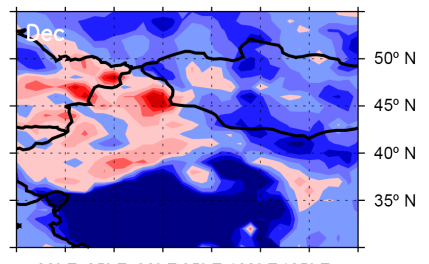

$80^{\circ} \mathrm{E} 85^{\circ} \mathrm{E} 90^{\circ} \mathrm{E} 95^{\circ} \mathrm{E} 100^{\circ} \mathrm{E} 105^{\circ} \mathrm{E}$

$\begin{array}{llllllllll}-2.0 & -1.5 & -1.0 & -0.5 & 0.0 & 0.5 & 1.0 & 1.5 & 2.0 & \left(\mathrm{~m} \mathrm{~s}^{-1}\right)\end{array}$

Figure 8. Annual cycle of the near-surface wind speed difference at 06:00 UTC between NLLJ and non-NLLJ days.

ward higher values when NLLJs are present compared to the days when there is no NLLJ. This result may be evidence of NLLJ effects on surface wind speed and a link between NLLJs and dust emission. However, if we take a further look at the detailed behavior of near-surface wind speed difference between jet and non-jet days for the seasonal cycle over the Tarim Basin, the spatial distributions of wind speed difference of each month are substantially different. In Fig. 8, we can see that positive differences are dominant in the basin during the cold season from October to March, but negative values are distributed over most of the basin area with only a weak positive belt aligning along the north slope of the Tibet Plateau during the period April to September. This seasonal contrast in the surface wind speed difference is exactly coincident with the relative position of jet height and inversion height that are shown in Fig. 6c. As we know, a convective boundary layer starts with morning insolation and grows gradually, dissipating the nocturnal surface inversion and transporting momentum from aloft to the surface. However, this process could be either very rapid or much slower depending on solar heating and other meteorological conditions. We may expect that, when the inversion layer is much thicker and the surface heating is very weak in the cold season, the development of mixed layer may be very slow, and the unstable layer happens to reach the height of NLLJ at 06:00 UTC. Thus, momentum from the LLJ is mixed down and leads to an increase in the surface wind speed, showing a positive difference during these months. By contrast, in the warm season, a mixed boundary layer is developed very rapidly, and LLJ momentum transport process may have been already largely completed by 06:00 UTC. The surface friction is well coupled with the boundary layer and consumes the downward momentum, eventually leading to a sub-geostrophic wind.

To test this hypothesis, we need to further investigate the height of convective boundary layer (CBL) in the midmorning (06:00 UTC). The Richardson number (Ri) (Richardson et al., 2013), which indicates the dynamic instability of the flow, is used here to determine the CBL height. The $R i$ is a measure of relative strength of buoyancy and mechanical wind shear. It is defined as

$R i=\frac{\frac{g}{\theta}\left(\frac{\partial \theta}{\partial z}\right)}{\left(\frac{\partial u}{\partial z}\right)^{2}+\left(\frac{\partial v}{\partial z}\right)^{2}}$,

where $\theta$ is the potential temperature, $g$ is the acceleration of gravity, $z$ is the height, and $u$ and $v$ are the horizontal wind velocity components. Clearly, turbulent energy increases when $R i<1$, but theoretical and experimental studies show that non-turbulent flow becomes turbulent when $R i$ drops below a critical value of around 0.25 . We first selected those profiles in which the potential temperature at the lowest level is larger than at the next higher level to ensure that the turbulence is induced by surface heating. Then we calculated the Ri numbers between successive levels for the selected profiles and searched each profile from the surface upwards, defining the lowest level, where $R i$ value exceeds the critical value of 0.25 , as the top of the CBL. The red lines 


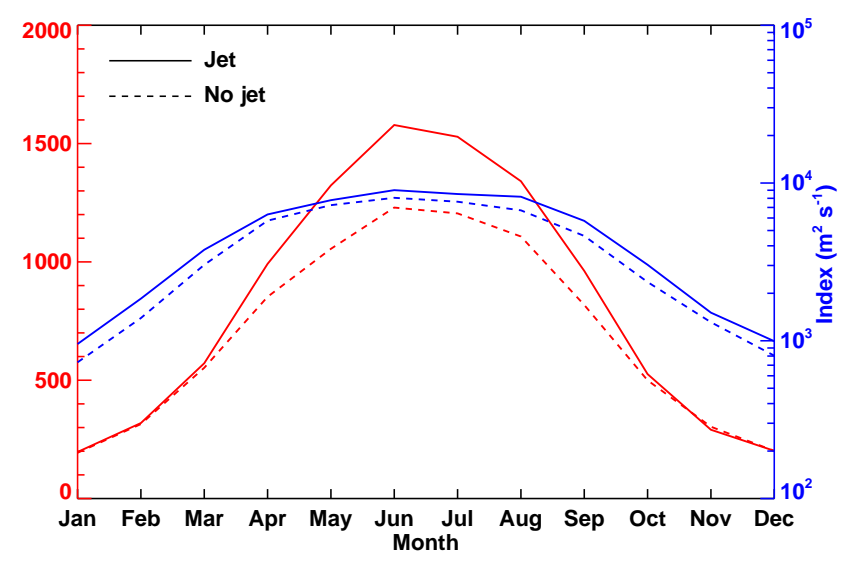

Figure 9. Monthly averaged convection boundary layer height at 06:00 UTC, and momentum index at 00:00 UTC over the TD.

in Fig. 9 plot the monthly variations in the CBL height at 06:00 UTC averaged on days with and without NLLJ over the TD. The variations for both jet and non-jet cases exhibit the same tendency, i.e., that the greatest heights appear in June and the lowest heights of about $200 \mathrm{~m}$ occur in December and January. The tendencies are clearly primarily a response to the solar insolation, which is the primary control of near-surface heating. During the cold season from October to March, the monthly mean CBL heights on jet days are almost the same as those on non-jet days and close to the jet core height. Significant differences in CBL heights between jet and non-jet days are evident in the months from April to September. We examined the occurrence of clouds and total cloud cover (TCC) derived from ERA-Interim data and found that the occurrence of both clouds and TCC on NLLJ days is much lower than non-jet days. It is clear that fewer clouds can let more thermal radiation escape to space and allow intense radiative cooling to form a stable surface layer during the night, leading to the development of NLLJ aloft. In the midmorning, fewer clouds also allow more solar radiation to reach at the surface and thus cause a stronger surface heating that consequently induces a stronger turbulence and a higher mixed layer than non-jet days. We may infer that stronger vertical mixing on days with jet occurrence can transport momentum between the surface and a given height in or above the stable layer rapidly in the warm season.

Having quantified the CBL height, we next quantified the magnitude of the momentum in the boundary by constructing an index. The index is a summation of wind speed from the height just above the surface layer to the height of the CBL, in units of $\mathrm{m}^{2} \mathrm{~s}^{-1}$ :

Index $=\int_{H_{\mathrm{s}}}^{H_{\mathrm{c}}} U(h) \mathrm{d} h$,

where $H_{\mathrm{s}}$ is the top of the surface layer, which is typically about $10 \%$ of the boundary layer depth and which we se- lected as the height of the third model level above the surface. $H_{\mathrm{c}}$ is the top of the CBL that is derived from $R i$ and $U(h)$ is the wind speed profile. We applied this index on each grid of ERA-Interim at 00:00 UTC and averaged the index values over the TD region. The blue lines in Fig. 9 show the monthly variations in the momentum index for days with and without NLLJ occurring at 00:00 UTC. The seasonal trends of the index are largely determined by the integral depth (i.e., the height of the CBL) and thus vary consistently with the CBL height. More importantly, the momentum index on days with NLLJs is always larger than that on days without NLLJs, even if there is no large difference in $H_{\mathrm{c}}$ between jet and non-jet cases. Note that, for both NLLJ and non-NLLJ cases, CBL heights during October through March are almost the same but are significantly different during the warm season. By combining the CBL height, momentum index, and nearsurface wind speed shown in Figs. 8 and 9, we may draw a conclusion that at night the boundary layer between $H_{\mathrm{S}}$ and $H_{\mathrm{c}}$ with NLLJ contains more momentum than without NLLJ. When the NLLJ breaks down in midmorning, its momentum is transported toward the surface, decreasing the speed aloft but producing stronger surface winds. During the cold season, the inversion depth is greater and vertical mixing is weaker, which consequently results in less downward momentum transfer occurring over a longer period of time. In the summer season, the downward momentum transfer process is more intense and rapid and could cause a significant increase in surface wind speed which is not captured by the 6-hourly ERA dataset.

The above investigation has indicated that the momentum in an upper boundary layer is larger and the turbulence is much stronger, especially in summer, for the NLLJ cases than without NLLJ occurrence. A larger momentum and stronger transfer consequently can lead to an enhancement of the surface wind speed. In order to explore a link between NLLJs and dust activity, a composite difference method is used to analyze the relationship between NLLJ winds and dust generation. We point out that if the wind profile composite is simply based on high and low dust loading, an enhancement of wind in the lower atmosphere will always be seen because larger wind speed is directly related to dust generation for a given surface condition. Thus, there is a risk of evaluating the effect of NLLJ on dust emission since we cannot tell whether stronger surface winds are associated with the NLLJ. To avoid this risk, we select only ERA-Interim data for which $80 \%$ of the grid points along the section at $40^{\circ} \mathrm{N}$ between the latitudes of 78 and $88^{\circ} \mathrm{E}$ are identified with the appearance of NLLJ. We then match the time series of the NLLJ data and AOD observations for the composite analysis. According to the seasonal distribution of AOD, we use the 10th and 90th percentile values of the AOD cumulative distribution function to identify the most and least dusty days, and 42 samples for winter and 58 samples for each of the other three seasons are picked out for the composite difference analysis. Figure 10 shows the seasonal composite differ- 

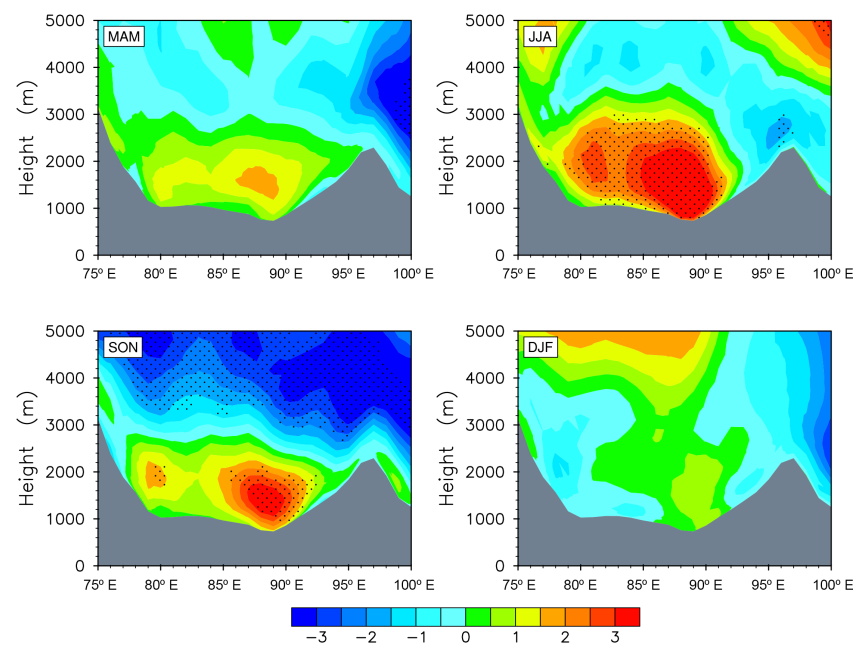

Figure 10. Seasonal longitudinal cross sections of daily wind composite difference between high and low AOD days along $40^{\circ} \mathrm{N}$. Stippled areas are significant at the $95 \%$ level. Gray areas represent terrain.

ences of latitudinal wind speed between the most and least dusty days along $40^{\circ} \mathrm{N}$. It is clear that the NLLJ is significantly enhanced on days of high AOD for the summer and autumn seasons and that the core speed increases by more than $3 \mathrm{~m} \mathrm{~s}^{-1}$. Due to stronger turbulent mixing in summer compared to other seasons, NLLJ level winds may affect the surface wind speed and variance, causing a deeper surface layer with a more significant increase in wind speed on highdust days in summer than autumn.

We also notice an interesting phenomenon: although AOD values are highest in spring (Fig. 2), NLLJ speeds are not significantly higher in this season. It is well known that a cold front with high synoptic-scale winds causes strong dust storms in spring (Sun et al., 2001). Our results clearly indicate that occurrences of NLLJ have relatively less influence on dust emission in the spring, when synoptic-scale winds dominate dust emission.

\section{Conclusion}

In this study, we presented a long-term, detailed structure of the wind profile in the atmospheric boundary layer over the Taklimakan Desert, which has a relatively flat terrain. A comparison of radiosondes and ERA-Interim reanalysis at two sites in the Tarim Basin shows that the reanalysis data can capture the feature of the low-level wind profile. Based on our NLLJ detection algorithm, NLLJs are frequent over the entire Tarim Basin and Taklimakan Desert throughout the entire year with an occurrence frequency above $60 \%$. The dominant wind directions are east and east-northeast in all seasons. The annual mean values of jet height and core speed are $270 \mathrm{~m}$ and $6 \mathrm{~m} \mathrm{~s}^{-1}$, respectively. The jet core height and speed show seasonal variations, with maximum values in August and minimum in January. The inversion height also changes with season, but in a manner opposite to the height of the jet core. We found that about $50 \%$ of the identified NLLJ cores are above the top of inversion (more frequently in the warmer season), and the other half were embedded in the inversion layer (mostly in the colder season).

The midmorning breakdown of the nocturnal inversion and jet core is a remarkable and consistent feature of NLLJ over the TD. The momentum of these NLLJs can be mixed downward, increasing surface wind speed, which could be the driving mechanism for dust emission over this and other arid regions. We calculated the CBL height and constructed an index to quantify the magnitude of the momentum from the top of the surface layer to the CBL height. It is found that the momentum in an upper boundary layer is larger for the NLLJ cases than without NLLJ occurrence in all seasons, while the CBL heights in the warm season are much greater than those in the cold season. This indicates that stronger vertical mixing on days with jet occurrence can transport more momentum between the surface and CBL height in the warm season, thus enhancing the surface wind speed.

We further matched the NLLJ and MISR AOD data and found that there was a significant enhancement of NLLJ during high-AOD days in the summer and autumn seasons, when the core speed increased by more than $3 \mathrm{~m} \mathrm{~s}^{-1}$. In the cold season, the sensible heat energy input is much less and the inversion layer is thicker, which causes much weaker downward propagation of turbulence, and thus NLLJs have a lesser effect on surface wind and dust activity in winter and spring.

NLLJs have been identified as a frequent mesoscale phenomenon over the TD and are possibly an important mechanism for dust activity, especially in the summer months. To define the details of the NLLJ diurnal cycle and to clarify the causal and quantitative relationships to dust emission and transport, further ground-based in situ and remote sensing measurements of winds and dust concentration profiles are needed along with high spatial and temporal resolution numerical modeling.

\section{Data availability}

The data for this paper are available at NASA Atmospheric Data Center and ECMWF. Datasets: MISR, ERA Interim. Data file name: MIL3DAE_*.004_*.hdf, ERA_Interim_*.nc (NASA Atmospheric Data Center, 2015; ECMWF, 2016).

Acknowledgements. This work was supported by the National Science Foundation of China (41275070, 41521004, 41575016), the China 111 project (no. B 13045), and the Fundamental Research Funds for the Central University (lzujbky-2015-K02). We thank Dave S. Covert for useful comments and discussion.

Edited by: Y. Balkanski 


\section{References}

Allen, C. J. T. and Washington, R.: The low-level jet dust emission mechanism in the central Sahara: Observations from BordjBadji Mokhtar during the June 2011 Fennec Intensive Observation Period, J. Geophys. Res.-Atmos., 119, 2990-3015, doi:10.1002/2013jd020594, 2014.

Andreas, E. L., Claffy, K. J., and Makshtas, A. P.: Lowlevel atmospheric jets and inversions over the western Weddell Sea, Bound.-Lay. Meteorol., 97, 459-486, doi:10.1023/a:1002793831076, 2000.

Baas, P., Bosveld, F. C., Baltink, H. K., and Holtslag, A. A. M.: A Climatology of Nocturnal Low-Level Jets at Cabauw, J. Appl. Meteorol. Clim., 48, 1627-1642, doi:10.1175/2009jamc1965.1, 2009.

Banta, R. M., Newsom, R. K., Lundquist, J. K., Pichugina, Y. L., Coulter, R. L., and Mahrt, L.: Nocturnal low-level jet characteristics over Kansas during CASES-99, Bound.-Lay. Meteorol., 105, 221-252, doi:10.1023/a:1019992330866, 2002.

Blackadar, A. K.: Boundary layer wind maxima and their significance for the growth of nocturnal inversions, B. Am. Meteorol. Soc., 83, 283-290, 1957.

Bonner, W. D.: Climatology of the low level jet, Mon. Weather Rev., 96, 833-850, 1968.

Chen, S., Huang, J., Zhao, C., Qian, Y., Leung, L. R., and Yang, B.: Modeling the transport and radiative forcing of Taklimakan dust over the Tibetan Plateau: A case study in the summer of 2006, J. Geophys. Res.-Atmos., 118, 797-812, doi:10.1002/jgrd.50122, 2013

Dee, D. P., Uppala, S. M., Simmons, A. J., Berrisford, P., Poli, P., Kobayashi, S., Andrae, U., Balmaseda, M. A., Balsamo, G., Bauer, P., Bechtold, P., Beljaars, A. C. M., van de Berg, L., Bidlot, J., Bormann, N., Delsol, C., Dragani, R., Fuentes, M., Geer, A. J., Haimberger, L., Healy, S. B., Hersbach, H., Hólm, E. V., Isaksen, L., Kållberg, P., Köhler, M., Matricardi, M., McNally, A. P., Monge-Sanz, B. M., Morcrette, J.-J., Park, B.-K., Peubey, C., de Rosnay, P., Tavolato, C., Thépaut, J.-N., and Vitart, F.: The ERA-Interim reanalysis: configuration and performance of the data assimilation system, Q. J. Roy. Meteor. Soc., 137, 553-597, doi:10.1002/qj.828, 2011

Diner, D. J., Martonchik, J. V., Kahn, R. A., Pinty, B., Gobron, N., Nelson, D. L., and Holben, B. N.: Using angular and spectral shape similarity constraints to improve MISR aerosol and surface retrievals over land, Remote Sens. Environ., 94, 155-171, doi:10.1016/j.rse.2004.09.009, 2005.

Du, Y., Zhang, Q., Chen, Y.-L., Zhao, Y., and Wang, X.: Numerical Simulations of Spatial Distributions and Diurnal Variations of Low-Level Jets in China during Early Summer, J. Climate, 27, 5747-5767, doi:10.1175/jcli-d-13-00571.1, 2014.

ECMWF: ERA-Interim, available at: http://apps.ecmwf.int/ datasets/, last access: 19 April 2016.

Fiedler, S., Schepanski, K., Heinold, B., Knippertz, P., and Tegen, I.: Climatology of nocturnal low-level jets over North Africa and implications for modeling mineral dust emission, J. Geophys. Res.-Atmos., 118, 6100-6121, doi:10.1002/jgrd.50394, 2013.

Fu, Q., Thorsen, T. J., Su, J., Ge, J. M., and Huang, J. P.: Test of Mie-based single-scattering properties of non-spherical dust aerosols in radiative flux calculations, J. Quant. Spectrosc. Ra., 110, 1640-1653, doi:10.1016/j.jqsrt.2009.03.010, 2009.
Gao, H. and Washington, R.: The spatial and temporal characteristics of TOMS AI over the Tarim Basin, China, Atmos. Environ., 43, 1106-1115, doi:10.1016/j.atmosenv.2008.11.013, 2009.

Ge, J. M., Su, J., Ackerman, T. P., Fu, Q., Huang, J. P., and Shi, J. S.: Dust aerosol optical properties retrieval and radiative forcing over northwestern China during the 2008 China-US joint field experiment, J. Geophys. Res.-Atmos., 115, D00K12, doi:10.1029/2009jd013263, 2010.

Ge, J. M., Huang, J. P., Su, J., Bi, J. R., and Fu, Q.: Shortwave radiative closure experiment and direct forcing of dust aerosol over northwestern China, Geophys. Res. Lett., 38, L24803, doi:10.1029/2011g1049571, 2011.

Ge, J. M., Huang,J. P., Xu, C. P., Qi, Y. L., and Liu, H. Y.: Characteristics of Taklimakan dust emission and distribution: A satellite and reanalysis field perspective, J. Geophys. Res.-Atmos., 119, 11772-11783, doi:10.1002/2014jd022280, 2014.

Ginoux, P., Chin, M., Tegen, I., Prospero, J. M., Holben, B., Dubovik, O., and Lin, S. J.: Sources and distributions of dust aerosols simulated with the GOCART model, J. Geophys. Res.Atmos., 106, 20255-20273, doi:10.1029/2000jd000053, 2001.

Heinold, B., Knippertz, P., and Beare, R. J.: Idealized large-eddy simulations of nocturnal low-level jets over subtropical desert regions and implications for dust-generating winds, Q. J. Roy. Meteor. Soc., 141, 1740-1752, doi:10.1002/qj.2475, 2015.

Huang, J., Minnis, P., Yi, Y., Tang, Q., Wang, X., Hu, Y., Liu, Z., Ayers, K., Trepte, C., and Winker, D.: Summer dust aerosols detected from CALIPSO over the Tibetan Plateau, Geophys. Res. Lett., 34, L18805, doi:10.1029/2007g1029938, 2007.

Huang, J., Minnis, P., Chen, B., Huang, Z., Liu, Z., Zhao, Q., Yi, Y., and Ayers, J. K.: Long-range transport and vertical structure of Asian dust from CALIPSO and surface measurements during PACDEX, J. Geophys. Res.-Atmos., 113, D23212, doi:10.1029/2008jd010620, 2008.

Huang, J., Fu, Q., Su, J., Tang, Q., Minnis, P., Hu, Y., Yi, Y., and Zhao, Q.: Taklimakan dust aerosol radiative heating derived from CALIPSO observations using the Fu-Liou radiation model with CERES constraints, Atmos. Chem. Phys., 9, 4011-4021, doi:10.5194/acp-9-4011-2009, 2009.

Huang, J., Wang, T., Wang, W., Li, Z., and Yan, H.: Climate effects of dust aerosols over East Asian arid and semiarid regions, J. Geophys. Res.-Atmos., 119, 11398-11416, doi:10.1002/2014jd021796, 2014.

Huang, J., Yu, H., Guan, X., Wang, G., and Guo, R.: Accelerated dryland expansion under climate change, Nature Climate Change, 6, 166-171, doi:10.1038/nclimate2837, 2016.

Kahl, J. D.: Characteristics of the low-level temperature inversion along the Alaskan Arctic coast, Int. J. Climatol., 10, 537-548, doi:10.1002/joc.3370100509, 1990.

Knippertz, P.: Dust emissions in the West African heat trough - the role of the diurnal cycle and of extratropical disturbances, Meteorol. Z., 17, 553-563, doi:10.1127/0941-2948/2008/0315, 2008.

Knippertz, P. and Todd, M. C.: Mineral dust aerosols over the Sahara: meteorological controls on emission and transport and implications for modeling, Rev. Geophys., 50, RG1007, doi:10.1029/2011rg000362, 2012.

Ling, X., Guo, W., and Fu, C.: Composite analysis of impacts of dust aerosols on surface atmospheric variables and energy budgets in a semiarid region of China, J. Geophys. Res.-Atmos., 119, 3107-3123, doi:10.1002/2013jd020274, 2014. 
Lohmann, U. and Feichter, J.: Global indirect aerosol effects: a review, Atmos. Chem. Phys., 5, 715-737, doi:10.5194/acp-5-7152005, 2005.

Lu, H. and Shao, Y. P.: A new model for dust emission by saltation bombardment, J. Geophys. Res.-Atmos., 104, 16827-16841, doi:10.1029/1999jd900169, 1999.

NASA Atmospheric Data Center: MISR, available at: https:// eosweb.larc.nasa.gov/project/misr/misr_table, last access: 8 January 2015

Ranjha, R., Svensson, G., Tjernstrom, M., and Semedo, A.: Global distribution and seasonal variability of coastal low-level jets derived from ERA-Interim reanalysis, Tellus A, 65, 20412, doi:10.3402/tellusa.v65i0.20412, 2013.

Richardson, H., Basu, S., and Holtslag, A. A. M.: Improving Stable Boundary-Layer Height Estimation Using a Stability-Dependent Critical Bulk Richardson Number, Bound.-Lay. Meteorol., 148, 93-109, doi:10.1007/s10546-013-9812-3, 2013.

Rife, D. L., Pinto, J. O., Monaghan, A. J., Davis, C. A., and Hannan, J. R.: Global Distribution and Characteristics of Diurnally Varying Low-Level Jets, J. Climate, 23, 5041-5064, doi:10.1175/2010jcli3514.1, 2010 .

Schepanski, K., Tegen, I., Todd, M. C., Heinold, B., Boenisch, G., Laurent, B., and Macke, A.: Meteorological processes forcing Saharan dust emission inferred from MSG-SEVIRI observations of subdaily dust source activation and numerical models, J. Geophys. Res.-Atmos., 114, D10201, doi:10.1029/2008jd010325, 2009.

Shao, Y., Wyrwoll, K.-H., Chappell, A., Huang, J., Lin, Z., McTainsh, G. H., Mikami, M., Tanaka, T. Y., Wang, X., and Yoon, S.: Dust cycle: An emerging core theme in Earth system science, Aeolian Research, 2, 181-204, doi:10.1016/j.aeolia.2011.02.001, 2011.

Stensrud, D. J.: Importance of low-level jets to climate: A review, J. Climate, 9, 1698-1711, doi:10.1175/15200442(1996)009<1698:iolljt>2.0.co;2, 1996.

Stull, R. B.: An Introduction to Boundary Layer Meteorology, Kluwer Academic, 666 pp., Dordrecht, the Netherlands, 1988.

Su, J., Huang, J., Fu, Q., Minnis, P., Ge, J., and Bi, J.: Estimation of Asian dust aerosol effect on cloud radiation forcing using FuLiou radiative model and CERES measurements, Atmos. Chem. Phys., 8, 2763-2771, doi:10.5194/acp-8-2763-2008, 2008.
Sun, J. M., Zhang, M. Y., and Liu, T. S.: Spatial and temporal characteristics of dust storms in China and its surrounding regions, 1960-1999: Relations to source area and climate, J. Geophys. Res.-Atmos., 106, 10325-10333, doi:10.1029/2000jd900665, 2001.

Tegen, I.: Modeling the mineral dust aerosol cycle in the climate system, Quaternary Sci. Rev., 22, 1821-1834, doi:10.1016/s0277-3791(03)00163-x, 2003.

Tegen, I., Schepanski, K., and Heinold, B.: Comparing two years of Saharan dust source activation obtained by regional modelling and satellite observations, Atmos. Chem. Phys., 13, 2381-2390, doi:10.5194/acp-13-2381-2013, 2013.

Todd, M. C., Washington, R., Raghavan, S., Lizcano, G., and Knippertz, P.: Regional model simulations of the Bodele low-level jet of northern Chad during the Bodele Dust Experiment (BoDEx 2005), J. Climate, 21, 995-1012, doi:10.1175/2007jcli1766.1, 2008.

Uno, I., Eguchi, K., Yumimoto, K., Takemura, T., Shimizu, A., Uematsu, M., Liu, Z., Wang, Z., Hara, Y., and Sugimoto, N.: Asian dust transported one full circuit around the globe, Nat. Geosci., 2, 557-560, doi:10.1038/ngeo583, 2009.

Van de Wiel, B. J. H., Moene, A. F., Steeneveld, G. J., Baas, P., Bosveld, F. C., and Holtslag, A. A. M.: A Conceptual View on Inertial Oscillations and Nocturnal Low-Level Jets, J. Atmos. Sci., 67 2679-2689, doi:10.1175/2010jas3289.1, 2010.

Washington, R. and Todd, M. C.: Atmospheric controls on mineral dust emission from the Bodele Depression, Chad: The role of the low level jet, Geophys. Res. Lett., 32, L17701, doi:10.1029/2005g1023597, 2005.

Yumimoto, K., Eguchi, K., Uno, I., Takemura, T., Liu, Z., Shimizu, A., and Sugimoto, N.: An elevated large-scale dust veil from the Taklimakan Desert: Intercontinental transport and three-dimensional structure as captured by CALIPSO and regional and global models, Atmos. Chem. Phys., 9, 8545-8558, doi:10.5194/acp-9-8545-2009, 2009.

Zhang, X. Y., Gong, S. L., Zhao, T. L., Arimoto, R., Wang, Y. Q., and Zhou, Z. J.: Sources of Asian dust and role of climate change versus desertification in Asian dust emission, Geophys. Res. Lett., 30, 2272, doi:10.1029/2003gl018206, 2003. 